\title{
Centenário de \\ Paulo Freire: entrevista com Moacir Gadotti
}

\author{
Ismar de Oliveira Soares
}

Professor titular sênior da Escola de Comunicação e Artes da Universidade de São Paulo (ECA-USP) e presidente da Associação Brasileira de Pesquisadores e Profissionais em

Educomunicação (ABPEducom - www.abpeducom.org.br).

E-mail: ismarolive@yahoo.com.

Resumo: Moacir Gadotti completou 80 anos em outubro deste ano em plena atividade. O professor é licenciado em pedagogia e filosofia, mestre em filosofia da educação pela PUC-SP, doutor em ciências da educação pela Universidade de Genebra, na Suiça, e livre-docente pela Universidade de Campinas. Atualmente está aposentado da Faculdade de Educação da USP e é presidente de honra do Instituto Paulo Freire. Nesta entrevista a Ismar Soares, Gadotti nos presenteia com uma recuperação histórica da trajetória de Paulo Freire, com quem compartilhou uma longa relação de proximidade e amizade. Traz também um generoso relato das suas impressões sobre o autor e suas obras e explica como o Instituto está revisitando Paulo Freire ao pensar na educação do futuro a partir da sua práxis.

Palavras-chave: Moacir Gadotti; Paulo Freire; Instituto Paulo Freire; centenário de Paulo Freire; comunicação e educação.
Abstract: In October of this year, Moacir Gadotti turned 80 in full activity. Author of several works and owner of an extensive curriculum, the professor holds a teaching degree in Pedagogy and Philosophy, is Master in Philosophy of Education from PUC-SP, a PhD in Educational Sciences from the University of Geneva, Switzerland, and an associate professor at the University of Campinas. Currently, Gadotti is retired from the Faculty of Education of the USP and is an honorary president of the Paulo Freire Institute, where he has worked since 1991. In this interview with Ismar Soares, the author performs a historical recovery of the trajectory of Paulo Freire, with whom he shared a long friendship. Gadotti also reports his impressions on the author and his works, explaining how the Institute revisits Paulo Freire when thinking future education from Freire's praxis.

Keywords: Moacir Gadotti; Paulo Freire; Paulo Freire Institute; centenary of Paulo Freire; communication and education. 


\section{INTRODUÇÃO}

Moacir Gadotti, professor aposentado da FEUSP e presidente de honra do Instituto Paulo Freire, concedeu entrevista especial ao presente dossiê. Trata-se do especialista mais próximo ao mestre Paulo Freire, tendo com ele convivido desde 1974, quando o conheceu em Genebra. Moacir Gadotti é autor de Paulo Freire: uma biobibliografia (Cortez, 1996) e coordenou a coletânea Reinventando Paulo Freire, conjuntamente com Martin Carnoy (IPF, 2018). Sobre o amigo, Gadotti afirma que tudo o que Paulo Freire escreveu é autobiográfico, não sendo possível, portanto, estabelecer qualquer hierarquização a respeito de sua própria produção. Gadotti explica que Freire foi influenciado por diferentes correntes de pensamento (do personalismo cristão ao marxismo), mas o que há de original nele é a afirmação da subjetividade como condição da revolução, da transformação social. Daí o papel da educação como conscientização.

Perguntado sobre a relação de Freire com a comunicação, Gadotti reconhece que para ele não era possível separar educação de comunicação. A pergunta levou Gadotti a se aproximar do tema da educomunicação: "Lembro, com emoção, de ter sido entrevistado diversas vezes por jovens adolescentes vinculados ao Projeto Educom.rádio. Com um gravador na mão, eles se sentiam como lutadores e lutadoras por um outro mundo possível. Isso é maravilhoso". Ao comentar o impacto da obra de Freire a nível mundial, Gadotti garante que "a contribuição de Paulo Freire ao pensamento educativo mundial não se limita ao que ele diretamente escreveu e realizou, mas ao que se está fazendo com o seu legado, em todas as partes do mundo".

No final da entrevista, Moacir Gadotti revelou um fato desconhecido por muitos: "Freire, ao partir em 1997, deixou na sua mesa de trabalho um texto inacabado sobre ecologia. Talvez estivesse pensando em escrever um novo capítulo que faltava à Pedagogia do oprimido: o da "pachamama oprimida", uma pedagogia da Terra, uma "ecopedagogia". Veja, na sequência, a íntegra da entrevista.

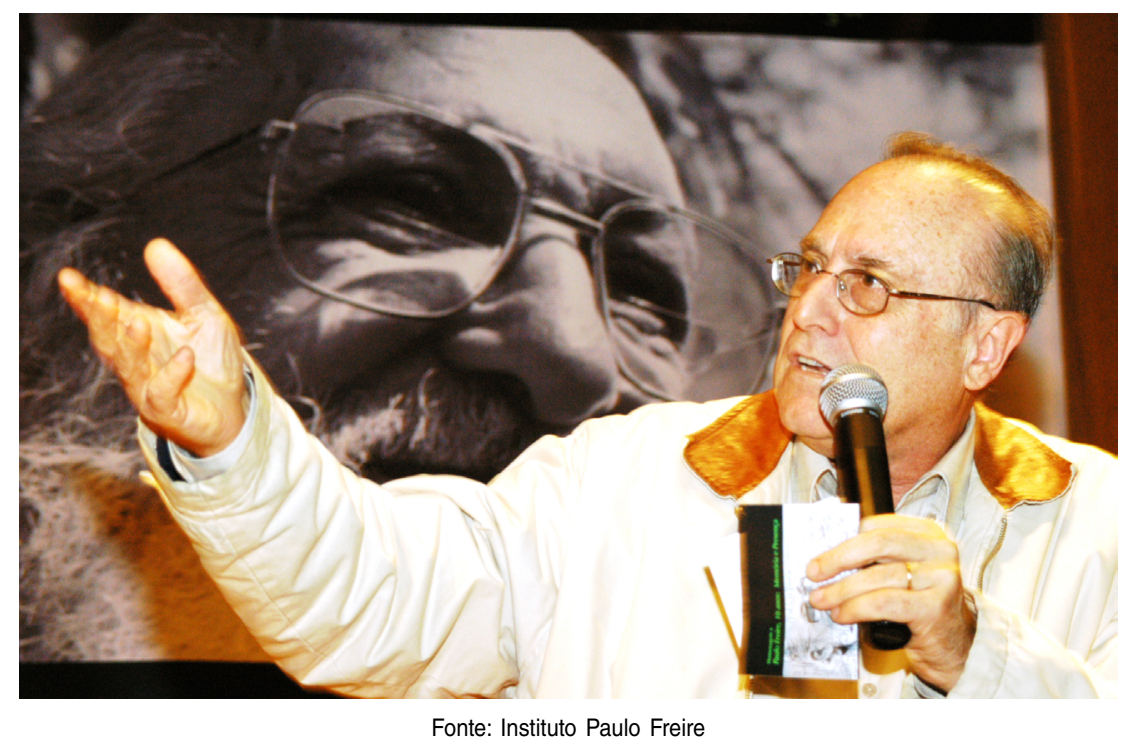


comunicação \& educação • Ano XXVI • número 2 • jul/dez 2021

Comunicação \& Educação: Sua aproximação à trajetória de Paulo Freire teve início em 1974, em Genebra, antecedendo, portanto, o retorno do mestre ao Brasil. Que expectativas Freire alimentava em relação a uma possível volta ao país natal nos anos iniciais da chamada "abertura lenta e gradual"? Tinha algum projeto especial?

Moacir Gadotti: Em 1977, eu estava em Genebra, planejando voltar ao Brasil, quando recebi um convite para lecionar na recém-criada Universidade Estadual de Campinas (Unicamp). Paulo Freire me confidenciou que se pudesse também voltaria, mas tinha receio de sofrer novas perseguições políticas. Como você disse, tratava-se de uma abertura "lenta e gradual". Se ele voltasse com um contrato com uma universidade pública, ele se sentiria mais seguro. Ele temia represálias de um ciclo autoritário que não havia sido ainda fechado.

Ao retornar ao Brasil, no final daquele ano, eu procurei a Universidade de São Paulo (USP) e a Unicamp para falar sobre o assunto. O diretor da Faculdade de Educação da Unicamp encaminhou a proposta de sua contratação, que foi plenamente aceita pelos órgãos internos da faculdade, mas a tramitação do processo foi retardada pelo reitor da universidade. Alunos e professores da Faculdade de Educação fizeram, então, várias manifestações públicas para exigir a contratação de Freire. Nesse ínterim, Dom Paulo Evaristo Arns, grão-chanceler da Pontifícia Universidade Católica de São Paulo (PUC-SP), começou as negociações para trazer Paulo Freire e contratá-lo. Contudo, as dificuldades não eram apenas de contratação. $O$ governo brasileiro negava a anistia a oito brasileiros. Entre eles, Paulo Freire.

Em 1978, Paulo havia sido convidado para abrir um seminário nacional de educação no Brasil, precisamente em Campinas, mas lhe negaram o passaporte para regressar. Contudo, por uma dessas artimanhas muito bem montadas pela Comissão Organizadora do evento, Paulo Freire pôde fazer, "clandestinamente" (por telefone), a abertura do I Seminário de Educação Brasileira, em setembro daquele ano. Era a primeira vez que os educadores se reuniam livremente desde o início da ditadura civil-militar (1964), a primeira vez que estavam ouvindo a voz de Paulo Freire. Sua voz soava misteriosa e subversiva. Foi um marco do retorno de Paulo Freire. Ele falou de sua alegria de se dirigir aos professores brasileiros depois de 14 anos de exílio. Sua fala foi emocionada, afirmando que sua palavra "não poderia ser outra, senão uma palavra afetiva, uma palavra de amor, uma palavra de carinho, uma palavra de confiança, de esperança e de saudades também, saudade imensa, grandona, saudades do Brasil, desse Brasil gostoso, desse Brasil de nós todos, desse Brasil cheiroso, distante do qual estamos há 14 anos, mas, distante do qual nunca estivemos também”. Paulo estava com saudades e queria retornar, mas, sem o passaporte, era impossível. Aqui dentro, a luta pela anistia ganhava cada vez mais espaço nas ruas e na mídia progressista, e o governo militar teve que ceder.

No ano seguinte, finalmente, Paulo e sua esposa Elza puderam retornar ao país. No dia 20 de junho de 1979, antes de voltar, Paulo me escrevia de Genebra: "que vontade danada de dar um pulinho até aí; vontade mais danada 
ainda de, aproveitando o pulinho, ficar aí. Se o problema de nossos passaportes já tivesse sido resolvido, nossa intenção era ir aí logo que terminasse o seminário que vou coordenar na Universidade de Michigan no mês de julho. Tudo indica, porém, que visitaremos o Brasil este ano ainda. O nosso advogado está absolutamente convencido de que, durante o mês de julho, ganharemos o mandado de segurança. Se assim acontecer, estaremos aí talvez em setembro, desde que possamos enfrentar as despesas com as passagens". No dia 7 de agosto de 1979, ele voltaria ao Brasil pela primeira vez depois do exílio e, definitivamente, no ano seguinte.

Nessas duas falas de Paulo Freire, podemos perceber quais eram suas expectativas, bem como seus temores e seus projetos. Em resumo, poderia dizer que ele, antes de mais nada, queria "reaprender o Brasil", como afirmou ao chegar, e desejava mais: retomar o sonho interrompido brutalmente pelo golpe de 1964 de uma educação pública popular, como ele havia feito ao construir o Programa Nacional de Alfabetização.

C\&E: Ao longo de aproximadamente cinco décadas, você pode acompanhar o cotidiano da vida de Freire e certamente testemunhou seus sonhos e expectativas, fato que justificou a biobibliografia que produziu sobre o amigo, em 1996. Nesse período, chegou a identificar alguma hierarquização que Paulo fazia a respeito de sua própria produção? Que obras Paulo acreditava serem indispensáveis para que seu pensamento fosse suficientemente conhecido?

MG: Conheci Paulo Freire pessoalmente em Genebra, em 1974. O contato com a sua obra era anterior, 1967, quando ele publicou Educação como prática da liberdade, sobre o qual fiz meu trabalho final de Licenciatura em Pedagogia, em São Paulo, concluída no mesmo ano. Comecei a trabalhar com ele a partir de 1974. Primeiramente, foram as trocas de ideias sobre a situação brasileira, 10 anos depois do golpe de 1964. Engajamo-nos em campanhas para auxiliar refugiados políticos. Foram muitos os encontros na cantina do Conselho Mundial de Igrejas onde ele trabalhava. Ele sempre tratava a todos com enorme cortesia e paciência, sempre sonhando com algo, projetando algo, atendendo a inúmeros estudantes, professores e outros profissionais de vários países, dando entrevistas, lendo e escrevendo, discutindo. Assim nasce Paulo Freire, o cidadão do mundo.

Em 1977, ele participou da banca de meu doutoramento na Universidade de Genebra, ao lado de Pierre Furter e Pierre Dominicé, conhecidos intelectuais dedicados ao tema da educação permanente e de adultos. O que me chamou a atenção, desde os primeiros contatos com o Paulo, foi a indissociabilidade entre vida e obra. Minhas lembranças mostram-me algo que está presente sempre em seu pensamento, em toda a sua trajetória: a coerência entre teoria e prática. Costumo dizer que tudo o que ele escreveu é autobiográfico, tamanha a presença do autor em seus escritos, que têm a marca da sua autoria muito forte, comprometida, muito pessoal. Não posso dizer que ele estabelecia qualquer hierarquização a respeito de sua própria produção, considerando uma obra mais importante do que outra. O que escrevia fazia parte de seu modo de ser no mundo. Tudo fazia parte de um mesmo sonho. Como ele disse numa 
entrevista concedida ao Museu da Pessoa de São Paulo, em 1992: "o meu sonho fundamental é o sonho pela liberdade que me estimula a brigar pela justiça. O meu sonho é que nós inventemos uma sociedade menos feia e menos injusta do que a nossa de hoje. O meu sonho é um sonho da bondade e da beleza".

C\&E: Freire era identificado como um "católico radical" que não hesitava em dialogar com correntes progressistas do pensamento. Nessa linha, tenho duas questões: seria possível afirmar que na obra Pedagogia do oprimido existe uma espécie de convergência entre o humanismo cristão e certa linhagem marxiana, na qual se destacam Lukács, Althusser, Che Guevara, entre outros? E tal ecumenismo representaria ao mesmo tempo uma atitude de abertura para as diferenças e a tentativa de promover sínteses dialéticas e um compromisso com o destino do ser humano, considerando as circunstâncias objetivas de sua existência?

MG: Paulo Freire já foi comparado com muitos educadores e sua pedagogia foi entendida de diversas maneiras. Ele não só influenciou muitos pensadores, como foi influenciado por outros. Sofreu influências diversas: seu pensamento humanista inspirou-se no personalismo cristão, bem como no existencialismo, na fenomenologia e no marxismo. Embora não se possa falar com muita propriedade de fases do pensamento freiriano, pode-se dizer que a influência do marxismo se deu depois da influência humanista cristã. São momentos distintos, mas não contraditórios. Como afirma o filósofo alemão Wolfdietrich SchmiedKowarzik em seu livro Pedagogia dialética: de Aristóteles a Paulo Freire, ele combina temas cristãos e marxistas na sua pedagogia dialético-dialógica. Trata-se de um pensador da cultura, um dialético.

A educação é uma prática antropológica por natureza, portanto ético-política. Por essa razão, pode se tornar uma prática libertadora. O que há de original em Freire, com relação ao marxismo ortodoxo, é que ele afirma a subjetividade como condição da revolução, da transformação social. Daí o papel da educação como conscientização. A associação entre o humanismo e o marxismo enriquece seus textos e faz que eles sejam lidos por um público muito diverso. Seu pensamento representa a síntese de fontes diferentes, o que coloca, para o leitor iniciante, o problema de apreendê-lo de forma global. No livro Paulo Freire: uma biobibliografia (p. 441), que você mencionou, faço referência a uma entrevista na qual ele diz:

o que eu tentei fazer com a conscientização foi insistir na relação contraditória entre subjetividade e objetividade na história. Sem dúvida, Marx nos deixou muitas reflexões sobre esse tema, mas muitos dos seus leitores distorceram suas palavras; esqueceram o papel da subjetividade na história, com medo de cair no idealismo. Tentando escapar do idealismo eles caíram num objetivismo mecanicista. Muitos de nós, da esquerda progressista, estamos repensando o papel da consciência frente à liberdade, sem ficar com medo da liberdade na história.

Ao introduzir a categoria "conscientização" na leitura de Marx, ele estava reinventando o marxismo. Uma sociedade de iguais e diferentes, uma sociedade socialista, não pode ser construída sem respeitar a individualidade, as diferenças, enfim, a subjetividade humana. 
C\&E: Em 1978, o pesquisador Luis Ramiro Beltrán, em seu trabalho Adiós a Aristóteles: comunicación horizontal, identificou Freire como o fundador de uma nova teoria da comunicação, rompendo com a visão funcionalista que imperava no Ocidente, desde os tempos do filósofo grego. Os estudos de Beltrán, somados à contribuição de um número significativo de autores e gestores de projetos culturais, no continente, permitiu ao Núcleo de Comunicação e Educação da ECA/USP apontar, em 1998, para o surgimento de um campo de interface entre a comunicação e a educação, a que denominou educomunicação, e que hoje oferece sustentação para a mobilização de um grande contingente de lideranças comunitárias e de estudantes secundaristas e universitários (muitos destes, com o apoio de políticas públicas) em torno a uma comunicação dialógica capaz de mobilizar pessoas e organizações na defesa de temas de interesse coletivo, como é o caso da defesa do meio ambiente e dos direitos humanos. No entanto, o livro que o senhor editou, em 1996, sob o título Paulo Freire: uma biobibliografia, com 765 páginas e mais de uma centena de autores, não garante destaque para o tema da comunicação, registrando apenas a manifestação de quatro autores: Carlos Crespo Burgos ("Paulo Freire e as teorias da comunicação"); Werner E. Breede ("Paulo Freire e os computadores"), Jorge Vasconcelos e Paulo Freire ("Rádio e educação") e de Venício Lima, este com três participações ("Ideias de Paulo Freire sobre comunicação", "Teoria dialógica da comunicação" e "Conceito de comunicação em Paulo Freire"). Para os estudiosos de Paulo Freire, a comunicação seria um tema menor?

MG: Todos conhecemos as dificuldades que os pesquisadores encontram na busca de informações sobre um determinado assunto, sobretudo quando ainda não existiam as ferramentas digitais de busca de hoje. Esse foi o meu caso, no final da década de 1980 e no início da década de 1990, quando pesquisei em uma centena de universidades e centros de estudos e pesquisas a extensão da obra de Paulo Freire no mundo, que eu poderia alcançar, naquele momento por meio de cartas e telefonemas a colegas e amigos de outros países, alguns deles indicados pelo próprio Paulo Freire. Admardo Serafim de Oliveira me deu acesso a uma base de dados por ele levantada que atualizei na medida do possível. Se eu fizesse esse levantamento hoje, o resultado seria outro.

Lembro de entregar o livro impresso ao Paulo no Centro de Referência Paulo Freire, em São Paulo, e ele me dizer que não tinha ideia de que haviam escrito tanto sobre ele e como os escritos dele haviam chegado em lugares em que ele sequer tinha conhecimento. Deixo a Paulo Freire a resposta à pergunta que você me fez. Na página 493 do livro Paulo Freire: uma biobibliografia, respondendo pergunta semelhante de Jorge Vasconcelos, da Rádio CBN, em 1984, Paulo Freire diz que, como educador, jamais deixou "entre parênteses os chamados meios de comunicação, que infelizmente, na sua maioria, viraram meios de comunicados". Citando a contribuição dada às escolas radiofônicas do Nordeste, diz ele que não tinha dúvida de que "é possível fazer um ótimo trabalho educativo" pelo rádio. "O grande problema do rádio e da televisão 
não está nem em um nem em outro. O problema é a favor de quem e contra quem estão os meios de comunicação, pois eles não são neutros”. Paulo Freire associava a educação à cultura, entendendo a primeira como um ato cultural e de comunicação. Reinventou o conceito de "aula", chamando-o de "círculo de cultura" e não de "círculo de educação". Associava o diálogo à comunicação, distinguindo a "comunicação dialógica" da comunicação "vertical" que ele chamava de "comunicados". A "comunicação autêntica" se estabelece por meio do diálogo pelo qual um indivíduo pode transformar-se em criador e sujeito de sua própria história. O diálogo pertence à natureza mesma do ser humano enquanto ser da comunicação. Nesse sentido, não é possível separar educação de comunicação.

Fico feliz com essa pergunta que me permitiu revisitar o livro Paulo Freire: uma biobibliografia e ver o quanto somos limitados em nossos tempos-espaços. Com a criação do Instituto Paulo Freire, tivemos a oportunidade de acompanhar diversos projetos de educomunicação, em estreita colaboração com o professor Ismar de Oliveira Soares. A prática educomunicativa, inspirada em Paulo Freire, levada à frente em numerosos projetos, entre eles o Educom.rádio, desenvolvido em escolas públicas do ensino fundamental do município de São Paulo (2001-2004), mostrou o quanto podemos fazer no campo do protagonismo infantojuvenil, que é também o campo da educação cidadã, como educação em direitos humanos. Lembro, com emoção, de ter sido entrevistado por jovens adolescentes, em diversas ocasiões, alunos e alunas da prefeitura de São Paulo. Com um gravador na mão, eles se sentiam como lutadores e lutadoras por um outro mundo possível. Isso é maravilhoso. Sou testemunha desse poder encantador da mídia, utilizada para empoderar pessoas e transformar o mundo. Muito foi feito. Muito falta ainda a fazer.

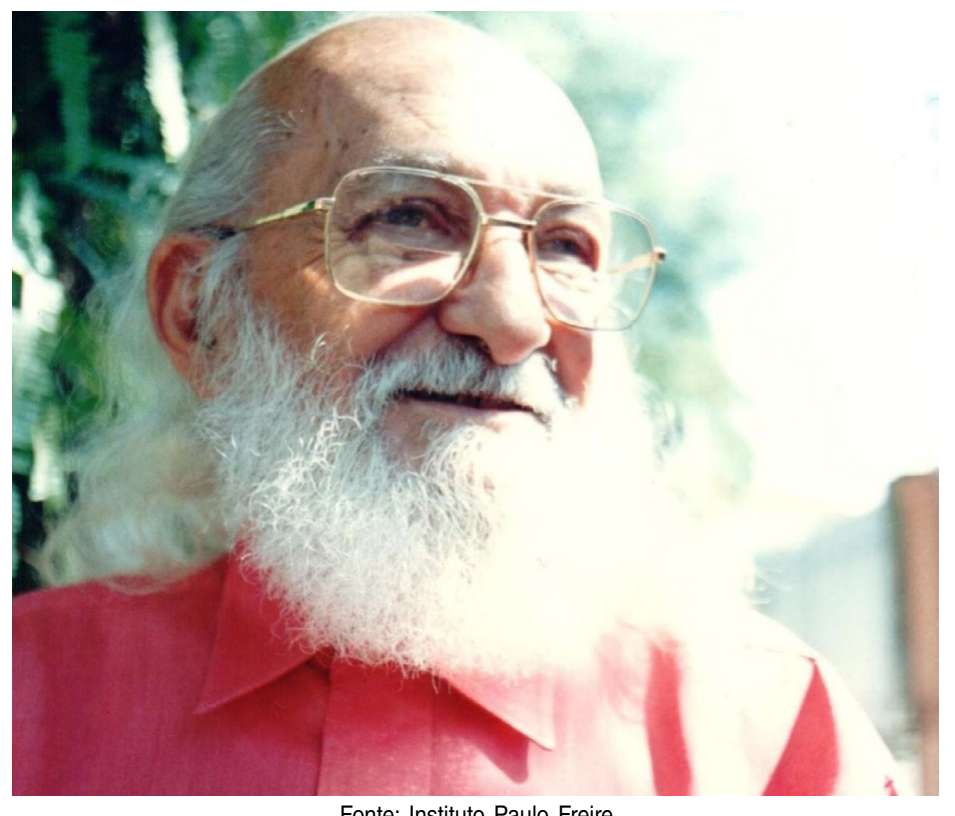


C\&E: O pensamento freiriano contou, em várias partes do mundo, ao longo das últimas décadas, com uma recepção positiva que levou à fundação de institutos destinados a incentivar estudos e experimentos voltados à educação como prática da liberdade. Qual tem sido a incidência destes centros tanto na formação de educadores quanto na definição de políticas de educação (básica e superior), em nível internacional?

MG: A contribuição de Paulo Freire ao pensamento educativo mundial não se limita ao que ele diretamente escreveu ou realizou, mas ao que se está fazendo com seu legado. O que vem sendo feito, por exemplo, pelos Institutos Paulo Freire e pelas Cátedras Paulo Freire, entre outros grupos e instituições que estão dando continuidade e reinventando sua obra, é também extremamente relevante hoje ao analisarmos a trajetória intelectual e política de Freire.

Embora ele parta de uma realidade latino-americana, Freire não se limita a ela. Ele dialoga com outras realidades e, assim, elabora uma teoria complexa. A pedagogia de Paulo Freire adquiriu um significado universal, uma vez que a relação oprimido-opressor, que ele abordou, ocorre universalmente e suas teorias se enriqueceram com as mais variadas experiências e práticas em diversas partes do mundo. Sua obra teórica tem servido como fundamento de trabalhos acadêmicos e inspirado práticas em diversas partes do mundo, passando pelas mais consagradas instituições educacionais do Brasil e de outros países. Tal influência abrange as mais diversas áreas do saber: a pedagogia, a filosofia, a teologia, a antropologia, o serviço social, a ecologia, a medicina, a psicoterapia, a psicologia, a museologia, a história, o jornalismo, as artes plásticas, o teatro, a música, a educação física, a sociologia, a pesquisa participante, a metodologia do ensino de ciências e letras, a filologia, a ciência política, o currículo escolar e, é claro, a educação em direitos humanos.

A crescente publicação das obras de Paulo Freire em dezenas de idiomas e a ampliação de fóruns, cátedras e centros de pesquisa criados para pesquisar e debater seu legado, bem como o número de trabalhos escritos sobre ele, são indicações da grande vitalidade do seu pensamento. Tal projeção confere ao conjunto de suas produções o caráter de uma obra universal com incidência internacional. Em outubro de 2017, com o nome "Coleção Paulo Freire", custodiada pelo Instituto Paulo Freire e por Ana Maria Araújo Freire, seu acervo foi incluído no Registro Internacional do Programa Memória do Mundo da Unesco e reconhecido como patrimônio documental da humanidade. Não podemos ver Freire apenas como um educador de adultos ou como um acadêmico, ou reduzir sua obra a uma técnica ou metodologia. As intuições originais de Paulo Freire marcaram a educação contemporânea. Entre elas: a reflexão crítica sobre a prática como base para a construção do conhecimento; o reconhecimento da legitimidade do saber popular; um método de conhecimento e de pesquisa que parte da leitura do mundo; uma teoria do conhecimento fundamentada numa antropologia; enfim, uma ciência aberta às necessidades populares. Essas e outras contribuições de Paulo Freire à compreensão do ato educativo são hoje reconhecidas mundo afora e continuam muito atuais. Ele recusa o pensamento 
fatalista e propõe uma pedagogia comprometida com a cidadania e a ética como referenciais básicos na busca pela radicalização da democracia. $\mathrm{O}$ pensamento freiriano é rebelde, insurgente, no qual não falta a indignação e a esperança, a crítica e a proposta. Ele dizia que estava nadando contra a correnteza.

É certo, muitos governos, em todos os níveis, em diferentes momentos e em várias partes do mundo, têm sido influenciados por ideias de Paulo Freire e implementado projetos emancipadores, mas o modelo educativo global dominante no mundo é o da meritocracia, essencialmente injusto, que não leva em conta as diferenças. Paulo Freire, em toda a sua trajetória, pensava numa política pública de educação popular, transformadora, o oposto da educação bancária meritocrática. Falta muito para que ela se transforme numa política pública.

C\&E: O conceito freiriano de diálogo, base para a prática educomunicativa, tem sido às vezes questionado, merecendo reparos por parte de estudiosos que o consideram um tanto idealista diante dos embates que se fazem necessários numa sociedade dominada por perspectivas iluministas e funcionalistas nas diferentes trocas comunicativas. Você vê procedência nesta afirmativa?

MG: Vou começar a resposta a esta pergunta por uma pequena história. Paulo Freire pediu-me para prefaciar o livro Educação e mudança, publicado em 1981. Trata-se de um livro cheio de esperança, de amor e de luta. Ele cita Erich Fromm, Malinowski, Zevedei Barbu, seus amigos de Recife Jomard Muniz de Britto e Jarbas Maciel e, quando fala da alfabetização como um ato criador, faz referência a "um jovem sociólogo brasileiro", o professor da Universidade de São Paulo Celso de Rui Beisiegel, um de seus primeiros colaboradores no sul do Brasil e grande amigo. Mostrei-lhe a primeira versão do meu prefácio. Paulo gostou muito dele porque, dizia-me, eu não estava simplesmente elogiando o autor do livro, mas estava contribuindo para entender melhor a noção de diálogo e sua impossibilidade prática entre classes antagônicas. Como todo prefaciador novato, intitulei, pretensiosamente, o meu escrito de "Educação e ordem classista". Claro, também queria responder a um segmento de intelectuais brasileiros - que poderiam sim ser chamados de iluministas e funcionalistas - os quais consideravam a obra de Paulo Freire como ingênua ou como muito "liberal", segundo alguns. Eu falava da relação entre mudança, conscientização, diálogo e conflito. Falava dos limites da conscientização e do diálogo na mudança, problematizando o título do livro, e me perguntando: pode a educação operar a mudança? Que mudança? Dizia que Paulo Freire combate a concepção ingênua da pedagogia que se crê motor ou alavanca da transformação social e política. Combate igualmente a concepção oposta, o pessimismo sociológico que consiste em dizer que a educação reproduz mecanicamente a sociedade. O diálogo que se limita à sala de aula como na pedagogia iluminista e suas vertentes "conteudistas", em que o político é reduzido ao pedagógico, certamente não incidirá na transformação social. O que eu tentava mostrar é que o diálogo não exclui o conflito como algo antagônico.

Paulo Freire gostou tanto desse prefácio que me convidou, pouco depois, para escrever um "livro dialogado", o primeiro de tantos que ele escreveu. 
Assim nasceu o livro Pedagogia: diálogo e conflito, publicado em 1985. Paulo Freire havia lido Martin Buber, para o qual o diálogo exigia duas condições: reciprocidade e igualdade de condições, isso existe entre iguais e diferentes e não entre antagônicos. Entre antagônicos o que há é o conflito. Esses são os limites do diálogo. A pedagogia do diálogo fundamenta-se numa filosofia pluralista, um pluralismo que não se confunde com ecletismo. Não se confunde com palavras "adocicadas", como ele costumava dizer: significa ter um ponto de vista e, a partir dele, dialogar com os demais. Essa foi a resposta que ele deu à crítica que recebeu sobre a natureza do diálogo nesse livro. Como era do seu feitio, sem entrar em polêmicas estéreis.

C\&E: Desde a primeira edição do Fórum Social Mundial (FSM), realizada em 2001 na cidade de Porto Alegre, no Rio Grande do Sul, pudemos observar diferentes articulações entre movimentos sociais e populares em busca de um projeto comum, antagônico ao neoliberalismo. Entre os elementos de intersecção, temos a luta em defesa da natureza e dos recursos naturais por articulações mundiais e continentais, como a Via Campesina e a Aliança Bolivariana das Américas (Alba), dos movimentos sociais. A partir de suas contribuições sobre ecopedagogia e da obra de Paulo Freire, como enxerga a questão da luta pela natureza e esse debate em torno de um projeto em defesa do comum contra o neoliberalismo na contemporaneidade?

MG: Essa é uma pergunta ampla e complexa que envolve diversos elementos. Todas essas temáticas podem ser vistas a partir do mote do FSM: "um outro mundo é possível". E poderíamos acrescentar: para um outro mundo possível, uma outra educação é necessária. O FSM foi criado por conta dos movimentos sociais e da educação popular que se consolidou como essa outra educação possível com as valiosas contribuições de Paulo Freire. É um processo global que tende a se multiplicar pelo mundo como espaço de libertação. Não é uma instituição ou uma organização. Só assim ele pode cumprir sua missão de incorporar de forma pluralista todos os setores que se identificam com a luta contra o neoliberalismo e pela radicalização da democracia.

Nos anos 1990, depois da queda do Império Soviético, o globalismo, com seu discurso único, queria selar o fim da história e matar a esperança. Um certo vazio ideológico deixou muita gente perplexa, sem chão, sem bandeiras de luta. O FSM ocupou esse espaço ideológico, reacendeu a esperança da libertação, recolocou a ideologia no palco da história. No FSM, prezamos a diferença e a diversidade como riquezas da humanidade. A educação, sem dúvida, pode se tornar instrumento de mudança das condições humanas. Educar para construir o sonho me parece hoje buscar um novo sentido para a educação, para que ela contribua para a reinvenção da democracia, como dizia Paulo Freire.

A noção de democracia precisa ser renovada, já que o modelo dominante neoliberal está confundindo nossas cabeças, substituindo o papel do Estado pelo Mercado e a cidadania pela sociedade de consumo, reduzindo a democracia à mera representação política, numa sociedade cada vez mais manipulada por veículos de comunicação nas mãos de uma pequena elite conservadora. O Mercado 
valoriza a competitividade frente aos valores democráticos. Em contrapartida, nós não renunciamos à utopia, à educação que forma seres humanos capazes de construir novas realidades, mais democráticas e justas socialmente. O embate é, ao mesmo tempo, social e ambiental. A Terra também é um organismo vivo e, como tal, quando adotamos um estilo de vida que a destrói, também se torna um oprimido, o maior de todos.

Paulo Freire, ao nos deixar, em 1997, deixou igualmente na sua mesa de trabalho um texto inacabado sobre ecologia. Talvez estivesse pensando em escrever um novo capítulo que faltava à Pedagogia do oprimido: o da pachamama oprimida, uma pedagogia da Terra, uma ecopedagogia. Passamos de um modo de produção para um modo de destruição do planeta. Daí a importância do debate por uma educação para a cidadania global e planetária. O tema é complexo. Há visões diferentes, provavelmente complementares. Enquanto a cidadania global está mais preocupada com a convivência dos seres humanos no planeta, a cidadania planetária se preocupa com a existência de toda a comunidade de vida do planeta, e do próprio planeta como um ser vivo. De nossa parte, temos procurado estabelecer pontes, diálogos e complementaridade entre essas visões, considerando-as como uma riqueza de conceitos e práticas e não como deficiências. Para alguns, o cidadão planetário é o guardião da Terra que pode nunca ter saído da sua aldeia e não ter a menor ideia do que é a Unesco, que lançou, há poucos anos, as bases de uma educação para a cidadania global. Não vemos oposição entre um cidadão global, sujeito de direitos universais, sem fronteiras, e um cidadão planetário, com um profundo sentimento de pertencimento à Terra. Apesar de diferentes, esses dois conceitos convergem em alguns pontos e, muitas vezes, se identificam. E aqui entra a questão dos bens comuns que podemos distinguir entre os bens comuns da Humanidade e os bens comuns do planeta Terra.

A Terra e a Humanidade fazem parte de um único universo em evolução e têm o mesmo destino, hoje ameaçado pelo modo irresponsável com que os terráqueos produzem e reproduzem sua existência no planeta. Os bens comuns da Terra e da Humanidade são inseparáveis. A questão central para nós é a criação de uma cidadania multicultural democrática global que facilite uma educação para a democracia. Como construir melhores escolas, escolas intelectualmente mais ricas, particularmente para aqueles que estão na base da sociedade? Como construir um currículo de cidadania multicultural democrática global, em que todos aprendem com a rica diversidade da sociedade e as tendências para o separatismo nas sociedades modernas podem ser prevenidas e até revertidas? Podemos fazer um trabalho melhor na preparação de professores para que as escolas se tornem núcleos de experiências coletivas e de solidariedade? Nossa resposta e nossa aposta estão na construção de uma educação para a cidadania global e planetária, mesmo que isso pareça um sonho impossível. Só a busca do que parece utópico tornará possível uma nova realidade em nossas vidas.

É para isso que o Instituto Paulo Freire vem trabalhando na pauta socioambiental, como membro do Conselho Internacional do FSM e no Fórum Mundial de Educação, promovendo a discussão da Carta da Terra e do Tratado da educação 
ambiental para as sociedades sustentáveis e a responsabilidade global, resultantes dos debates na Rio-92. Em 2002, as Nações Unidas lançaram a Década da educação para o desenvolvimento sustentável (2005-2014), que promovemos em muitas de nossas atividades, mesmo mostrando suas limitações. $\mathrm{O}$ mundo está se mobilizando, de diferentes maneiras, para evitar o pior. Contudo, as preocupações persistem e os grandes desafios ainda não foram superados.

C\&E: Em 2018, o Instituto Paulo Freire inaugurava a TV IPF e o senhor lançava a coletânea Reinventando Freire, em coordenação com o escritor norte-americano Martin Carnoy. O que significa "reinventar Freire" no início da terceira década do século XXI?

MG: Paulo Freire dizia que não queria ser seguido, mas reinventado. Nada menos freiriano do que ser seguidor de ideias, como nos tem dito Carlos Rodrigues Brandão. Paulo Freire nos deixou um espírito, um legado a ser ressignificado em cada contexto e reinventado permanentemente.

Foi nesse sentido que aceitei o desafio que Martin Carnoy me lançou de organizar um livro sobre essa experiência de reinvenção levada à frente pelo Instituto Paulo Freire em seus 30 anos de existência. Eu e Martin conhecemos Paulo Freire na década de 1970. Paulo Freire gostou muito do livro por ele publicado na época, Educação como imperialismo cultural. Um pouco depois, eu publiquei o livro A educação contra a educação sobre o relatório Aprender a ser, da Unesco, com temáticas muito próximas. Paulo Freire estava profundamente interessado nos desdobramentos do processo de internacionalização da educação que estava em curso naquele momento histórico. Viu no livro do Carnoy um relato contundente das consequências dessa internacionalização no momento em que ele estava assessorando a reconstrução de alguns sistemas nacionais de educação de países recém libertados da colonização, onde se debatia o tema da educação de adultos como educação permanente, que, mais tarde, seria entendida como educação ao longo da vida.

Foi naquele contexto que eu estava em diálogo com Paulo Freire sobre a temática do meu doutorado, no qual eu apontava os limites do projeto de educação permanente proposto pela Organização para a Cooperação e Desenvolvimento (OCDE) e pela Unesco. Mais de 40 anos depois, relembrando nosso encontro com Paulo Freire, buscamos revisitá-lo, pensando na educação do futuro a partir da práxis do instituto que leva seu nome. O resultado está no livro que organizamos com um grupo de mais de 60 convidados: Reinventando Freire: a práxis do Instituto Paulo Freire.

A educação no mundo passa por uma crise grave, associada à crise civilizatória atual, e Paulo Freire pode ser uma inspiração para o surgimento de novas políticas públicas de educação. Relendo agora este livro, não mais como um dos organizadores do trabalho, mas como leitor, eu vejo que os autores e autoras conseguiram demonstrar que Paulo Freire continua oferecendo contribuições e pistas importantes para entendermos os desafios atuais.

O mundo se globalizou e se estreitou pelo avanço das tecnologias, mas também se distanciou no trato do humano, no respeito, valorização e convivência 
com as diferenças, bem como do reconhecimento das semelhanças culturais. A visão humanista de Freire é um referencial importante para superarmos esse distanciamento. Não se trata, agora, de repetir suas ideias como discípulos. Trata-se, muito mais, de anunciar uma outra educação possível, profundamente engajada no presente e nos seus desafios atuais, num embate recriador do mundo.

Encontramos no pensamento freiriano muitos elementos, princípios e valores, que podem contribuir para a reinvenção da educação atual. Essa reinvenção da educação passa pela recuperação dos educadores como agentes e sujeitos do processo de ensino-aprendizagem e da prática educativa. Ela só pode ser obra de um esforço coletivo, colaborativo, plural, não sectário, pensando numa transição gradual para outras formas de conceber os sistemas educacionais, seu planejamento, sua gestão e monitoramento, seus parâmetros curriculares, se quisermos dar uma contribuição significativa para a construção de novas políticas públicas de educação. Educadores e educadoras podem e devem ser os principais protagonistas dessa reinvenção. A mudança precisa partir do vivido, do experimentado, do que está em processo, da "reflexão crítica sobre a prática", como diz Paulo Freire. Ele nos dizia que não podemos mudar a história sem conhecimento, mas que tínhamos que educar o conhecimento para colocá-lo a serviço da transformação social. Educar o conhecimento pelo entendimento da politicidade do conhecimento, isto é, pelo entendimento do sentido histórico e político do conhecimento.

Ao assumir a Secretaria Municipal de Educação de São Paulo, no dia 2 de janeiro de 1989, ele nos falava da necessidade de inverter as prioridades, da necessidade de mudar a cara da escola. Uma escola com uma nova cara não deveria ser avaliada por padrões meritocráticos, mas por outros padrões: a qualidade não deveria ser medida apenas pelos palmos de saber sistematizado que forem apreendidos, mas também pelos laços de solidariedade que podem ser criados entre os que ensinam e aprendem com sentido.

Educar é reproduzir ou transformar, repetir servilmente aquilo que foi, optar pela segurança do conformismo, ou, ao contrário, fazer frente à ordem estabelecida e correr o risco da aventura; querer que o passado configure todo o futuro ou partir dele para construir outra coisa. Numa perspectiva emancipadora, educar é desequilibrar, duvidar, suspeitar, lutar, tomar partido, estar presente no mundo. Educar é posicionar-se, não se omitir. É conscientizar, desalienar, desfetichizar. Desafios não faltam. Sabemos disso e não nos intimidamos diante deles. Em tempos obscuros como os que vivemos hoje, de ascensão do neoconservadorismo, de ódio e de intolerância, nossa saída é reforçar a crença na nossa capacidade como educadoras e educadores, docentes e discentes, de enfrentá-los com lucidez e força. Se a inteligência da realidade histórica nos incita ao pessimismo, a nossa vontade política nos faz um convite ao otimismo. Educar, em seu sentido emancipador, sempre foi isso: um exercício de otimismo. 